\title{
PENGARUH KONSENTRASI NATRIUM ALGINAT TERHADAP GEL EKSTRAK DAUN TEH HIJAU (Camellia sinensis L.) SEBAGAI INHIBITOR TIROSINASE
}

\section{THE EFFECT OF SODIUM ALGINATE CONCENTRATION ON GREEN TEA LEAF (Camellia sinensis L.) EXTRACT GEL AS TIROSINASE INHIBITOR}

\author{
Hanifah Rahmi, Rizky Ramadhan, Naniek Setiadi Radjab \\ Fakultas Farmasi dan Sains, Universitas Muhammadiyah Prof. Dr. Hamka \\ Jl. Delima II/IV, Malaka Sari, Duren Sawit, Jakarta Timur \\ Email: hanifah_rahmi@uhamka.ac.id (Hanifah Rahmi)
}

\begin{abstract}
ABSTRAK
Daun teh hijau (Camellia sinensis L.) merupakan salah satu tanaman yang mengandung senyawa-senyawa polifenol seperti katekin dan galokatekin galat yang dapat digunakan sebagai inhibitor tirosinase. Dalam penelitian ini ekstrak daun teh hijau dibuat menjadi sediaan gel dengan menggunakan natrium alginat sebagai gelling agent. Penelitian ini bertujuan untuk mengetahui pengaruh variasi konsentrasi natrium alginat terhadap penghambatan tirosinase pada gel ekstrak daun teh hijau. Gel dibuat menjadi 3 formula dengan masing-masing konsentrasi natrium alginat berturut-turut sebesar $2 ; 2,5 ; 3 \%$. Ekstraksi daun teh hijau dilakukan dengan cara refluks menggunakan pelarut metanol $50 \%$. Hasil penelitian menunjukkan ketiga formula mempunyai nilai $\mathrm{IC}_{50}$ masing-masing sebesar 34,80; 23,27; 20,69 $\mu \mathrm{g} / \mathrm{mL}$. Kesimpulan penelitian ini, bahwa sediaan dengan natrium alginat $3 \%$ memberikan hasil penghambatan tirosinase yang paling baik dengan $\mathrm{IC}_{50}$ sebesar $20,69 \mu \mathrm{g} / \mathrm{mL}$.
\end{abstract}

Kata kunci: gel, daun teh hijau, natrium alginat, inhibitor tirosinase.

\section{ABSTRACT}

Green tea leaf (Camellia sinensis L.) is a great plant containing polyphenol compounds such as catechin and gallocatechin gallate that can be used as tyrosinase inhibitors. In this study, the green tea leaf extract made into gel dosage form using sodium alginate as a gelling agent. This research aimed to determine the effect of different sodium alginate concentrations on the physical stability of gel extract green leaf and to know the effect of gel formulation on tyrosinase inhibition. Gel made into 3 formulas with each concentration of sodium alginate of $2 ; 2.5 ; 3 \%$. The extraction of green tea leaves was performed by reflux using 50\% methanol solvent. The results showed that the three formulas did not occur in phase separation, and had $I C_{50}$ values of 34.80, 23.27, 20.69 $\mu \mathrm{g} / \mathrm{mL}$. The conclusion is gel dosage form with $3 \%$ sodium alginate gave the best inhibition of tyrosinase with $I C_{50}$ of $20.69 \mu \mathrm{g} / \mathrm{mL}$.

Key words: gel, green tea leaf, sodium alginate, tyrosinase inhibitor. 


\section{Pendahuluan}

Sinar matahari merupakan sumber energi yang berperan penting bagi kehidupan makhluk di bumi yang terbagi atas berbagai jenis, di antaranya sinar ultraviolet (UV) A, B, dan C. Namun, disamping efek yang menguntungkan, paparan sinar matahari yang melimpah dengan intensitas yang tinggi dapat menyebabkan hiperpigmentasi kulit sehingga kulit menjadi kusam dan bersisik. Efek tersebut terutama disebabkan oleh sinar UV A dan B (Lumempuow dkk., 2012).

Hiperpigmentasi merupakan suatu gangguan pada pigmen kulit wajah yang umum terjadi karena adanya peningkatan proses melanogenensis yang dapat menyebabkan penggelapan dari warna kulit. Selain itu peningkatan sintesis melanin secara lokal atau tidak merata dapat menyebabkan pigmentasi lokal atau noda hitam pada bagian tertentu dari wajah (Cayce, 2004). Salah satu cara untuk mencegah atau menghambat pembentukan melanin adalah dengan melakukan penghambatan aktivitas tirosinase (Lloyd, 2011).

Beberapa tahun terakhir ini telah banyak ekstrak tanaman yang diujikan sebagai penghambat tirosinase karena memiliki zat aktif seperti golongan flavonoid polifenol dan zat derivatif lainnya. Salah satunya adalah tanaman teh (Camellia sinensis L). Daun teh merupakan salah satu tanaman yang mempunyai aktivitas antihiperpigmentasi. Ekstrak daun teh mengandung senyawa-senyawa polifenol seperti katekin dan galokatekin galat yang memiliki aktivitas menghambat enzim tirosinase (Sangsrichan dan Ting, 2010).

Ekstrak daun teh diformulasikan dalam sediaan gel untuk mengefektifkan penggunaannya pada kulit. Bentuk sediaan gel ini memiliki kelebihan dibanding bentuk sediaan yang lainnya seperti efek pendinginan pada kulit saat digunakan, penampilan sediaan yang jernih dan elegan, pada permukaan di kulit setelah kering meninggalkan film tembus pandang, elastis, mudah dicuci dengan air, pelepasan obatnya baik, kemampuan penyebarannya pada kulit baik, dan relatif lebih stabil dalam penyimpanan (Lachman dkk., 1994). Menurut Wardiyah (2015) sediaan gel adalah sediaan yang lebih stabil dibandingkan dengan salep dan krim karena hasil evaluasi stabilitas fisik 
menunjukkan stabilitas fisik yang paling baik.

Umumnya sediaan gel mengandung komponen bahan pengembang (gelling agent), penahan lembab, antioksidan, bahan pengawet, dan sebagainya. Bahan dasar pembentuk gel harus dipilih sebaik mungkin agar dapat menghasilkan sediaan gel yang baik dan aman. Beberapa contoh bahan pembentuk gel adalah natrium alginat, gelatin, natrium karboksimetil selulosa, karbomer, dan lain lain (Voigt, 1994).

Penelitian ini menggunakan natrium alginat sebagai gelling agent. Natrium alginat diperoleh dari ganggang coklat yang mengandung bahan lendir sampai $40 \%$. Konsentrasi yang biasa digunakan untuk membentuk sediaan gel adalah $3-6 \%$. Natrium alginat paling stabil pada pH 4-7 (Voigt, 1994). Natrium dan kasium alginat digunakan dalam formulasi farmasi komersial. Gel natrium alginat menunjukkan penyebaran yang lebih superior dan memiliki sifat sebagai pelicin, tidak lengket, dan tidak berasa, serta menunjukkan sifat emolien (Agoes, 2012).

Menurut Utomo (2013) natrium alginat $2 \%$ memberikan stabilitas fisik terbaik dibandingkan dengan basis gel natrium karboksil metil selulosa pada gel rambut ekstrak daun urang aring (Eclipta prostrata). Berdasarkan hal tersebut maka dilakukan penelitian mengenai variasi konsentrasi natrium alginat sebagai gelling agent dalam sediaan gel serta mengetahui aktivitas penghambatan enzim tirosinase pada gel tersebut.

\section{Metode Penelitian}

Alat dan Bahan

Alat-alat yang digunakan adalah timbangan analitik (Sartorium, Adam), mikroskop (Yazumi), alat refluks, vacuum rotary evaporator (Eyela), oven (Memmert), pH meter (Le Motte), viskometer Brookfield, spektrofotometer UV-Vis (Shimadzhu), vortex mixer (Gemmi Industrial Corp.), autoklaf (Hirayama), dan alat-alat gelas lainnya.

Bahan-bahan yang digunakan antara lain serbuk simplisia teh hijau yang diperoleh dari Badan Penelitian Tanaman Rempah dan Obat (Balittro) Bogor, metanol 50\%, natrium alginat (Shandong Jiejing Group Corporation), metil paraben, propil paraben, propilenglikol (DOW Chemical Pasific), dimetil sulfoksida (Merck), akuades. Bahan untuk uji penghambatan tirosinase yaitu tirosinase mushroom (Sigma Aldrich), L-Dopa (Sigma Aldrich), 
kalium dihidrogen fosfat, dikalium hidrogen fosfat, dan akuades bebas $\mathrm{CO}_{2}$. Jalannya Penelitian

1. Determinasi tanaman dan pengumpulan bahan baku

Tanaman segar berupa tangkai dan daun teh diserahkan kepada Herbarium Bogoriense-Lembaga IImu Pengetahuan Indonesia (LIPI) Cibinong untuk dideterminasi kebenaran sampel yang digunakan. Determinasi ini dibutuhkan waktu selama 2 minggu sampai diperoleh hasil.

2. Karakterisasi serbuk simplisia secara mikroskopik

Serbuk diamati menggunakan mikroskop dengan melihat fragmen pengenal yang terdapat pada simplisia daun teh. Serbuk simplisia ditetesi dengan kloral hidrat, kemudian dipanaskan di atas lampu spiritus (tidak sampai mendidih) (Depkes RI, 1989).

3. Ekstraksi daun teh hijau

Ekstraksi dilakukan dengan cara refluks menggunakan pelarut metanol 50\%. Ekstrak dipekatkan menggunakan alat vacuum rotary evaporator dengan suhu $55^{\circ} \mathrm{C}$ hingga dihasilkan ekstrak kental yang masih dapat dituang, lalu ditimbang (Sangsrichan dan Ting, 2010).
4. Karakterisasi ekstrak daun teh hijau

Ekstrak diuji organoleptisnya selama 6 minggu yang meliputi bentuk, warna, dan bau terhadap ekstrak. Adapun dilakukan susut pengeringan pada ekstrak dengan menimbang sebanyak 2,0 gram ekstrak kental dan dikeringkan pada suhu $105{ }^{\circ} \mathrm{C}$ selama 30 menit atau sampai berat konstan yang dinyatakan dalam persen (Depkes RI, 2000).

5. Identifikasi senyawa

Ekstrak kental ditambahkan dengan $50 \mathrm{~mL}$ air panas, kemudian dipanaskan hingga mendidih selama 5 menit. Filtrat disaring (larutan uji). Larutan uji ditambahkan $\mathrm{FeCl}_{3} 3 \%$, terbentuk warna hitam (tanin positif), ditambahkan larutan gelatin 10\%, terbentuk endapan putih (tanin positif), ditambahkan larutan $\mathrm{NaCl}-$ gelatin (larutan gelatin 1\% dalam larutan $\mathrm{NaCl} 10 \%)$, terbentuk endapan putih (tanin positif) (Farnsworth, 1966; Trease, 1961). Larutan uji ditambahkan pereaksi Folin Ciocalteu, dipanaskan sebentar di atas penangas air, maka akan terjadi warna biru kehitaman (fenol positif) (Hanani, 2016).

6. Formula gel ekstrak daun teh hijau 
Tabel 1. Formula gel

\begin{tabular}{lcccc}
\hline \multicolumn{1}{c}{ Bahan } & Fungsi & $\begin{array}{c}\text { F1 } \\
\text { (\%) }\end{array}$ & $\begin{array}{c}\text { F2 } \\
\mathbf{( \% )}\end{array}$ & $\begin{array}{c}\text { F3 } \\
\text { (\%) }\end{array}$ \\
\hline Ekstrak daun teh hijau & Zat Aktif & 1 & 1 & 1 \\
Natrium alginat & Gelling agent & 2 & 2,5 & 3 \\
Dimetilsulfoksida & Penetration Enhancer & 0,6 & 0,6 & 0,6 \\
Propilenglikol & Humektan & 15 & 15 & 15 \\
Metil paraben & Pengawet & 0,18 & 0,18 & 0,18 \\
Propil paraben & Pengawet & 0,02 & 0,02 & 0,02 \\
Akuades ad & Pelarut & 100 & 100 & 100 \\
\hline
\end{tabular}

(Sumber: Rowe, 2009)

7. Uji aktivitas penghambatan tirosinase

$$
\text { Larutan blanko, kontrol, dan }
$$
sampel yang telah dibuat sesuai dengan komposisi (Tabel 2) selanjutnya dihomogenkan dan diinkubasi pada suhu ruang selama 10 menit. Pengukuran aktivitas enzim tirosinase pada larutan blanko, kontrol, dan sampel menggunakan metode spektrofotometri pada panjang gelombang $481 \mathrm{~nm}$.

Tabel 2. Komposisi larutan uji penghambatan tirosinase

\begin{tabular}{lcccccc}
\hline \multirow{2}{*}{ Nama Larutan } & \multicolumn{5}{c}{ Volume $(\boldsymbol{\mu L})$} \\
\cline { 2 - 6 } & Dapar & L-DOPA & Tirosinase & Sampel & Ekstrak & Basis Gel \\
\hline Kontrol normal & 1850 & 400 & 250 & - & - & - \\
Kontrol positif 100 ppm & 1750 & 400 & 250 & - & 100 & - \\
Kontrol negatif 100 ppm & 1750 & 400 & 250 & - & - & 100 \\
Sampel gel 25 ppm & 1750 & 400 & 250 & 100 & - & - \\
Sampel gel 50 ppm & 1750 & 400 & 250 & 100 & - & - \\
Sampel gel 75 ppm & 1750 & 400 & 250 & 100 & - & - \\
Sampel gel 100 ppm & 1750 & 400 & 250 & 100 & - & - \\
Sampel gel 125 ppm & 1750 & 400 & 250 & 100 & - & - \\
Sampel gel 150 ppm & 1750 & 400 & 250 & 100 & - & - \\
\hline
\end{tabular}

8. Perhitungan persentase penghambatan (\% inhibisi)

Pengukuran absorbansi ini dapat dihitung persentase inhibisi menggunakan rumus sebagai berikut:
$\%$ Inhibisi $=\frac{\mathrm{A}-\mathrm{B}}{\mathrm{A}} \times 100 \%$

Keterangan:

A : Serapan kontrol - serapan blanko

B : Serapan sampel 
Aktivitas penghambatan dari yang menunjukkan bahwa tanaman sampel uji ditentukan dengan $I_{50}$ yaitu konsentrasi dimana sampel uji menghambat aktivitas tirosinase sebesar $50 \%$. IC 50 dihitung dengan menggunakan persamaan regresi linier, log konsentrasi sampel sebagai sumbu $x$ dan probit \% inhibisi sebagai sumbu $y$, dari persamaan $y=b x \pm a$ dapat dihitung nilai $I_{50}$.

$$
\text { Rumus } \begin{aligned}
I_{50:} y & =b x \pm a \\
x & =(50-a): b
\end{aligned}
$$

Keterangan:

$\mathrm{a}=$ slope

$\mathrm{b}=$ intersep

9. Analisis data

Nilai absorbansi dari aktivitas penghambatan tirosinase dianalisis menggunakan persamaan regresi linear. Sumbu $x$ merupakan log konsentrasi sampel dan probit \% inhibisi sebagai sumbu y. Nilai $I_{50}$ dari sediaan dapat ditentukan dari persamaan garis ini.

\section{Hasil dan Pembahasan}

Tanaman segar berupa tangkai dan daun teh yang didapatkan dari Balittro dilakukan determinasi di Herbarium Bogoriense-Lembaga IImu Pengetahuan Indonesia (LIPI) Cibinong tersebut adalah daun teh (Camellia sinensis L.). Karakterisasi serbuk daun teh hijau secara mikroskopik bertujuan untuk memastikan kebenaran simplisia dengan mengamati fragmen pengenal dengan pemeriksaan di bawah mikroskop. Pada hasil pengamatan didapatkan fragmen rambut penutup, sel batu, berkas pembuluh penebalan tangga dan serabut, hablur kalsium oksalat, epidermis bawah dengan stomata, dan epidermis atas dengan selsel palisade yang sesuai dengan buku acuan.

Serbuk daun teh hijau diekstraksi menggunakan metode refluks. Keuntungan metode ini menghasilkan ekstraksi yang lebih baik dan sempurna (Hanani, 2016) disamping zat aktif yang terkandung tahan terhadap pemanasan, dan pada penelitian sebelumnya (Sangsrichan dan Ting, 2010) menggunakan metode refluks dalam mengekstraksi. Pelarut yang digunakan adalah metanol 50\%. Pelarut tersebut dipilih karena zat aktif yang ingin ditarik adalah senyawa polar dan pada penelitian sebelumnya pelarut yang digunakan adalah metanol 50\%. Ekstrak cair yang diperoleh kemudian dipekatkan dengan menggunakan 
vacuum rotary evaporator pada suhu 55

${ }^{\circ} \mathrm{C}$. Pemekatan bertujuan untuk memperoleh konsentrasi senyawa lebih besar dan memudahkan penyimpanan (Hanani, 2016).

Uji karakterisasi ekstrak meliputi pemeriksaan organoleptis yang dilakukan dengan menggunakan panca indera dalam mendeskripsikan bentuk, warna, dan bau. Dari hasil pengamatan, diketahui bahwa ekstrak daun teh hijau memiliki bentuk yang kental, warna cokelat tua, dan bau yang khas seperti teh. Selanjutnya dilakukan perhitungan rendemen dari ekstrak daun teh hijau dan didapatkan hasil sebesar 53,77\%.

Hasil identifikasi senyawa pada ekstrak kental daun teh hijau positif menunjukkan bahwa ekstrak mengandung tanin dan fenol, kedua senyawa ini mempunyai aktivitas penghambat tirosinase. Ekstrak daun teh hijau mengandung senyawa-senyawa polifenol seperti katekin dan galokatekin galat yang memiliki aktivitas menghambat enzim tirosinase (Sangsrichan dan Ting, 2010). Posisi fenol dari senyawa aktif ekstrak berikatan dengan atom $\mathrm{Cu}$ pada active site tirosinase menyebabkan tidak terjadi reaksi oksidasi yang dikatalisis tirosinase sehingga pembentukan senyawa dopakuinon dan dopakrom menjadi berkurang. Active site yang berikatan dengan $\mathrm{Cu}$ pada tirosinase yaitu pada posisi difenol.

Uji aktivitas tirosinase masingmasing larutan menggunakan spektrofotometer pada panjang gelombang $481 \mathrm{~nm}$. Panjang gelombang ini diperoleh dari penentuan panjang gelombang dengan serapan maksimum. Prinsip pengukuran aktivitas enzim tirosinase didasarkan pada reaksi yang dikatalisisnya, yaitu mengubah L-DOPA sebagai substrat menjadi dopakuinon yang kemudian berubah menjadi dopakrom sebagai produk berwarna yang dapat diukur kadarnya dengan spektrofotometer.

Gambar 1. menunjukkan hasil uji aktivitas tirosinase dengan menggunakan $2 \%$ natrium alginat pada berbagai konsentrasi ekstrak daun teh hijau. Aktivitas enzim mengalami penurunan ditandai dengan persentase penghambatan yang meningkat jika dibandingkan dengan kontrol positif dan negatif. Nilai $I_{50}$ yang diperoleh pada formula 1 sebesar $34,80 \mu \mathrm{g} / \mathrm{mL}$. Nilai ini berasal dari persamaan regresi linier $\mathrm{y}=$ $0,6168 x+4,0491$ 


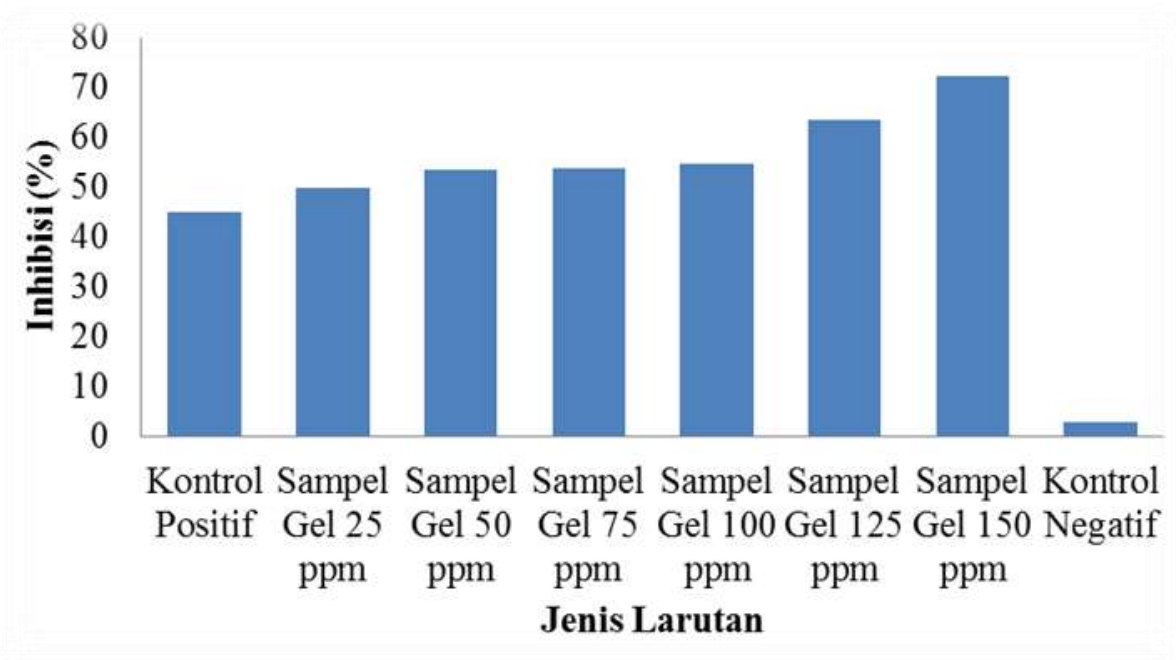

Gambar 1. Persentase inhibisi tirosinase formula 1.

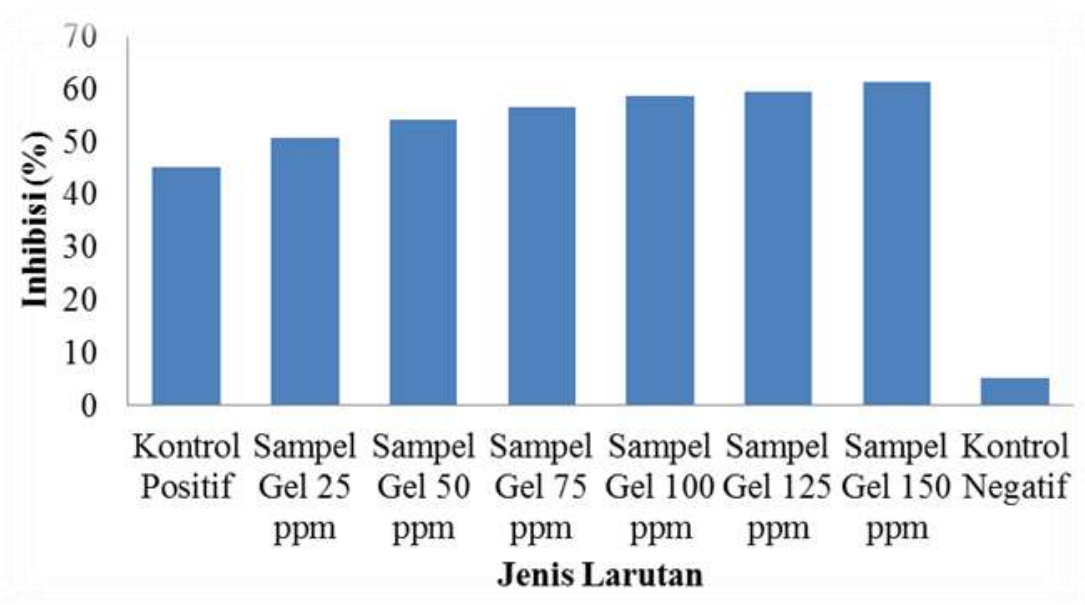

Gambar 2. Persentase inhibisi tirosinase formula 2.

Gambar 2 menunjukkan hasil uji aktivitas tirosinase dengan menggunakan $2,5 \%$ natrium alginat pada berbagai konsentrasi ekstrak daun teh hijau. Aktivitas enzim mengalami penurunan ditandai dengan persentase penghambatan yang meningkat jika dibandingkan dengan kontrol positif dan negatif. Nilai $I C_{50}$ yang diperoleh pada formula 1 sebesar 23,27 $\mu \mathrm{g} / \mathrm{mL}$. Nilai ini berasal dari persamaan regresi linier $\mathrm{y}=$ $0,3413 x+4,5335$ 


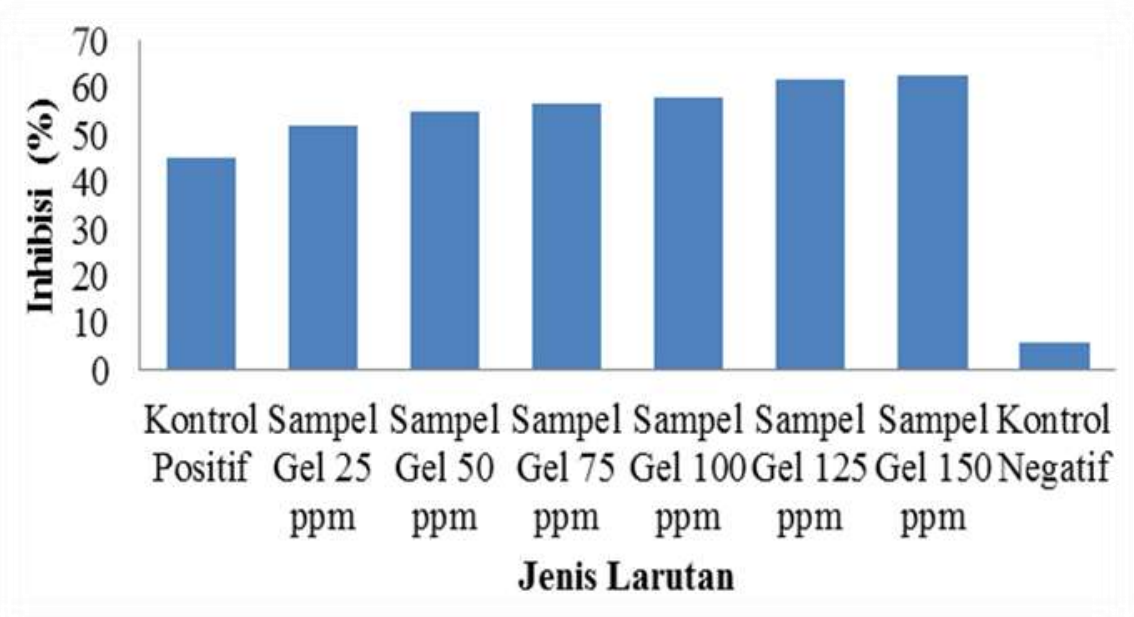

Gambar 3. Persentase inhibisi tirosinase formula 3.

Gambar 3 menunjukkan hasil uji aktivitas tirosinase dengan menggunakan $3 \%$ natrium alginat pada berbagai konsentrasi ekstrak daun teh hijau. Aktivitas enzim mengalami penurunan ditandai dengan persentase penghambatan yang meningkat jika dibandingkan dengan kontrol positif dan negatif. Nilai $\mathrm{IC}_{50}$ yang diperoleh pada formula 1 sebesar 20,69 $\mu \mathrm{g} / \mathrm{mL}$. Nilai ini berasal dari persamaan regresi linier $y=0,3501 x+4,5393$

Formula 3 merupakan formula terbaik karena memberikan nilai $I_{50}$ terendah dibandingkan formula 1 dan 2 . Ketiga formula gel ekstrak daun teh hijau menunjukkan bahwa penambahan natrium alginat sebagai gelling agent dapat meningkatkan penghambatan aktivitas enzim tirosinase, jika dibandingkan dengan ekstrak daun teh sebagai kontrol positif. Hal ini dapat dijelaskan karena natrium alginat merupakan polimer alam yang diekstrak dari rumput laut cokelat dan memiliki aktivitas antioksidan (Szekalska dkk., 2016). Hasil penelitian menunjukkan bahwa kombinasi ekstrak daun teh hijau dengan natrium alginat memberikan efek aditif terhadap kemampuan penghambatan aktivitas tirosinase yang belum dapat dijelaskan mekanisme reaksinya.

\section{KESIMPULAN}

Formulasi gel ekstrak daun teh hijau dengan gelling agent natrium alginat sebesar 2; 2,5; dan 3\% memiliki aktivitas penghambatan tirosinase. Masing-masing formula secara 
berurutan memiliki nilai $\mathrm{IC}_{50}$ sebesar 34,80; 23,27; dan 20,69 $\mu \mathrm{g} / \mathrm{mL}$. Sediaan dengan formula natrium alginat $3 \%$ memberikan hasil penghambatan tirosinase yang paling baik dengan $\mathrm{IC}_{50}$ sebesar 20,69 $\mu \mathrm{g} / \mathrm{mL}$.

\section{Daftar Pustaka}

Agoes, G. 2012. Sediaan Farmasi Likuida-Semisolida. Bandung: Penerbit ITB.

Cayce, K.A. 2004. Hyperpigmentation: an overview of the common affliction. Dermatol Nurs, 16(5):401-416.

Departemen Kesehatan Republik Indonesia. 1989. Materia Medika Indonesia Jilid 5. Jakarta: Departemen Kesehatan Republik Indonesia.

Departemen Kesehatan Republik Indonesia. 2000. Parameter Standar Umum Ekstrak Tumbuhan Obat. Jakarta: Direktorat Jenderal POM.

Farnsworth, N.R. 1966. Biological and Phytochemical Screening of Plants. USA: American Pharmaceutical Association.

Hanani, E. 2016. Analisis Fitokimia. Jakarta: EGC.

Lachman, L., Hobert, A.L., Joseph, L.K. 1994. Teori dan Praktek Farmasi Industri. Jilid 2 Edisi Ketiga, terjemahan: Siti Suyatmi. Jakarta: UI Press.
Lloyd, H.W. 2011. Treatment of hyperpigmentation. Semin Cutan Med Surg, 30(3):171-175.

Lumempuow, L.I., Edi, S., Jessy, J.E.P. 2012. Aktivitas anti UV-B ekstrak fenolik dari tongkol jagung (Zea mays L.). Jurnal MIPA UNSRAT Online, 1(1):1-4.

Rowe, R.C. 2009. Handbook of Pharmaceuticals Excipients. $6^{\text {th }}$ Edition. London: Pharmaceuticals Press and The American Pharmacist Association.

Sangsrichan, S., Ting, R. 2010. Antioxidation and radical scavenging activities and tyrosinase inhibition of fresh tea leaves Camellia sinensis L. Science Sci. J. UBU, 1(1):76-81.

Szekalska, M., Agata, P., Emilia, S., Patrycja, C., Katarzyna, W. 2016. Alginate: current use and future perspectives in pharmaceutical and biomedical applications. International Journal of Polymer Science, (1):1-17.

Trease, G.E. 1961. A Texbook of Phamacognosy. London: Bailliere, Tindal \& Cox.

Utomo, P.M. 2013. Optimasi perbandingan penggunaan natrium alginat dan natrium karboksimetil selulosa sebagai gelling agent terhadap stabilitas fisik gel rambut ekstrak daun urang aring (Eclipta prostrata). Skripsi. Fakultas Farmasi dan Sains, UHAMKA Jakarta. 
Voigt, R. 1994. Buku Pelajaran Teknologi Farmasi. Terjemahan: Soendani Noerono. Yogyakarta: UGM Press.

Wardiyah, S. 2015. Perbandingan sifat fisik krim, gel, dan salep yang mengandung etil metoksisinamat dari ekstrak rimpang kencur (Kaempferiae galangal L.). Skripsi. Fakultas Kedokteran dan IImu Kesehatan, UIN Syarif Hidayatullah Jakarta. 